\title{
Preliminary Testing of a Pressurized Space Suit and Candidate Fabrics under Simulated Mars Dust Storm and Dust Devil Conditions
}

\author{
James R. Gaier ${ }^{1}$ \\ NASA Glenn Research Center, Cleveland, OH 44135, USA \\ Pablo G. de León ${ }^{2}$ \\ University of North Dakota, Grand Forks, ND 58202, USA \\ Pascal Lee ${ }^{3}$ \\ Mars Institute, SETI Institute, and NASA Ames Research Center, Moffett Field, CA 94035, USA \\ Terry R. McCue \\ Arctic Slope Regional Corporation, Cleveland, OH 44136, USA \\ Edward W. Hodgson ${ }^{5}$ \\ Hamilton Sundstrand Space Systems International, Windsor Locks, CT 06096, USA \\ and \\ Jeff Thrasher ${ }^{6}$ \\ Yap Films, Toronto, Ontario, M5V 2J6, Canada
}

In August 2009 YAP Films (Toronto) received permission from all entities involved to create a documentary film illustrating what it might be like to be on the surface of Mars in a space suit during a dust storm or in a dust devil. The science consultants on this project utilized this opportunity to collect data which could be helpful to assess the durability of current space suit construction to the Martian environment. The NDX-1 prototype planetary space suit developed at the University of North Dakota was used in this study. The suit features a hard upper torso garment, and a soft lower torso and boots assembly. On top of that, a nylon-cotton outer layer is used to protect the suit from dust. Unmanned tests were carried out in the Martian Surface Wind Tunnel (MARSWIT) at the NASA Ames Research Center, with the suit pressurized to $10 \mathrm{kPa}$ gauge. These tests blasted the space suit upper torso and helmet, and a collection of nine candidate outer layer fabrics, with wind-borne simulant for five different 10 minute tests under both terrestrial and Martian surface pressures. The infiltration of the dust through the outer fabric of the space suit was photographically documented. The nine fabric samples were analyzed under light and electron microscopes for abrasion damage. Manned tests were carried out at Showbiz Studios (Van Nuys, CA) with the pressure maintained at $20 \pm 2 \mathrm{kPa}$ gauge. A large fancreated vortex lifted Martian dust simulant (Fullers Earth or JSC Mars-1) off of the floor, and one of the authors (Lee) wearing the NDX-1 space suit walked through it to judge both subjectively and objectively how the suit performed under these conditions. Both the procedures to scale the tests to Martian conditions and the results of the infiltration and abrasion studies will be discussed.

\footnotetext{
${ }^{1}$ Research Physicist, Space Environment and Experiments Branch, MS 309-2, NASA Glenn Research Center, 21000 Brookpark Road, Cleveland OH 44135, USA.

${ }^{2}$ Research Associate, Dept. of Space Studies, University of North Dakota, Grand Forks, ND 58202, USA.

${ }^{3}$ Chairman, Mars Institute, SETI Institute, and NASA Ames Research Center, Moffett Field, CA 94035, USA.

${ }^{4}$ Engineer IV, Arctic Slope Regional Corporation, MS 49-1, NASA Glenn Research Center, 21000 Brookpark Road, Cleveland OH 44135, USA.

${ }^{5}$ Technical Fellow, Hamilton Sundstrand Space Systems International, Windsor Locks, CT 06096, USA.

${ }^{6}$ Associate Producer, Yap Films, Toronto, Ontario, M5V 2J6, Canada. 


\section{Nomenclature}

$=$ dynamic pressure exerted by wind

$=$ atmospheric density

$=$ wind velocity

\section{Introduction}

It is articulated in the U.S. Space Policy that NASA will act to introduce a human presence to Mars during the first half of the 21 st Century. Although there have been several very successful robotic landers exploring the Martian surface, an entirely new set of challenges must be met to enable human exploration. One of those challenges is to develop a space suit that will enable astronauts to survive the harsh Martian conditions. One of the conditions that is of concern is the effects of dust on the space suit. It is known from the Apollo experience on the moon that dust can degrade a space suit in a number of ways including covering up sensitive surfaces, clogging mechanisms, compromising thermal control systems, and abrading both the outer fabric and the visor. ${ }^{1}$ This study was conceived as a way to start to investigate how severe these interactions may be on the Martian surface.

The surface of Mars is known to experience dust storms, some of which become global in extent and may last several weeks, ${ }^{2}$ and also dust devils, ${ }^{3}$ which are always local in extent but may be several tens of times as wide as their terrestrial counterparts. Both phenomena suspend, transport, and redistribute dust effectively on Mars, and can result in abrasion and dust-coating of space exploration hardware, although surface winds associated with dust storms and dust devils have also been observed to sweep spacecraft surfaces clear of dust (as observed on NASA's Mars Exploration Rovers). Dust storms and dust devils may also result in significant reductions or losses in visibility, both through transient and local optical thickening of the atmosphere and through the progressive and possibly irreversible alteration of optical surfaces (camera lenses, helmet visors). Human explorers on Mars will need to be prepared for the immediate dynamic and optical effects of dust storms and dust devils, but also for their effects on the transport of larger sand-sized particles, including the accumulation of drifts and dunes which will affect mobility. While surface wind patterns on Mars seem to follow generally unidirectional trends, many areas on Mars experience locally multiple and complex wind patterns. This makes dust and sand transport directions difficult to predict ${ }^{4}$ and therefore all the more important to be prepared for.

Little has been done to study the effects of Martian dust on space suit fabrics, but there is a report by Marshall et al., that is similar to the tests described here. ${ }^{5}$ They tested small materials patches $(3 \mathrm{~cm}$ diameter) in the Martian Surface Wind Tunnel (MARSWIT) at NASA Ames Research Center. Samples of materials used for gloves, boots, woven fabrics, and visors were placed 5 to $10 \mathrm{~cm}$ and $50 \mathrm{~cm}$ from the wind tunnel floor. The lower samples were thus within the boundary layer and the upper samples in the free stream. They were tested under $1 \mathrm{~atm}$ pressure and 10 mbar pressure air using Carbondale Red, JSC Mars-1, and quartz sand as Martian regolith simulants. Unfortunately, only general conclusions without data were presented in this extended abstract, and no more complete report was published. Generally they concluded that with smaller particles there was lots of adhesion but not much abrasion. They did not remove the adhered dust from the materials to look for evidence of abrasion.

The MARSWIT has also been used to study the interaction of wind-blown sand and dust with photovoltaic coverslip and radiator surface materials under Martian pressures. ${ }^{6}$ It was concluded in these studies that adhesion dominates when the particles are small, the wind velocity is low, and the angle of attack is either glancing or normal. Abrasion becomes important only when the particles are rather large, the wind velocity is high, and the angle of attack nears normal.

In August 2009 YAP Films (Toronto) received permission from all entities involved to create a documentary film illustrating what it might be like to be on the surface of Mars in a space suit during a dust storm or in a dust devil. The science consultants on the project utilized this opportunity to collect data which could be helpful to assess the durability of current space suit construction to the Martian environment. Since the primary goal was to create visually compelling footage, and the project operated under severe time and budget constraints, there were inevitable compromises that affect the science. Nevertheless, the results which are described herein were instructive.

\section{Methods and Materials}

The space suit used was the NDX-1 (North Dakota eXperimental 1) prototype planetary space suit developed at the Department of Space Studies of the University of North Dakota under a NASA grant. The suit features a hard upper torso garment, and a soft lower torso and boots assembly. On top of that, a nylon-cotton outer layer is used to protect the suit from dust. The suit was worn by one of the authors (Lee) during the dust devil simulation tests. But since the MARSWIT, in which the Martian dust storm simulation tests were conducted, is not man-rated, the suit was internally supported and pressurized to $7 \mathrm{kPa}$ gauge $(1 \mathrm{psig})$ for these tests.

Particles can be carried by the wind via three mechanisms. In the first, surface traction, particles move very close to the surface and are moved in a sliding or rolling motion. In the second, saltation, particles bounce along the surface, moving in trajectories with heights on the order of tens of $\mathrm{cm}$. In the third, suspension, particles remain aloft 
trapped in eddies of turbulent flow. Which mechanism a particle will follow depends on the force exerted on the particles by the wind. The force exerted on a particle depends on its cross sectional area and the dynamic pressure $(q)$ of the wind, which is equal to:

$$
q=1 / 2 \rho v^{2}
$$

Where $\rho$ is the density of the air, and $v$ is the air velocity. The density of air at atmospheric pressure is about $1.2 \mathrm{~kg} / \mathrm{m}^{3}$. The atmospheric pressure on Mars, as measured by the Viking landers, varies from 700 to $1000 \mathrm{~Pa},{ }^{8}$ and so is about one percent of terrestrial pressure. So terrestrial air at Martian pressures has a density of about $0.012 \mathrm{~kg} / \mathrm{m}^{3}$. This means that it requires 10 times the wind velocity on Mars to generate the same dynamic pressure as a given wind velocity on earth.

This introduces difficulties when trying to simulate the effects of windblown particles on the Martian surface on the abrasion of materials when working on Earth. Either the particle weight can be simulated by using particles with low density, or the particle mass can be simulated using particles of the same density. Having the correct particle weight simulates the wind-blown particle motion. Having the correct mass simulates the impact energy between the particle and the test material.

\section{A. MARSWIT Tests}

Dust-laden winds on Mars were simulated in the MARSWIT, a low pressure flow-through wind tunnel $14 \mathrm{~m}$ long, with a $1.3 \times 1.1 \mathrm{~m}$ test section located $5 \mathrm{~m}$ from the mouth. This flow-through wind tunnel is located in a $4000 \mathrm{~m}^{3}$ chamber which can be pumped down to pressures as low as $380 \mathrm{~Pa}$. Its characteristics have been described elsewhere. ${ }^{7}$

Since the test volume in the section of the MARSWIT is only about $1.1 \mathrm{~m}$ high, only part of the NDX-1 suit could be exposed in this facility. The lower torso and boots were secured behind the suit so that effectively the suit was exposed from the waist up. Foam supports were placed in the suit and a mannequin head in the helmet. After the suit was transferred to the MARSWIT, it was inflated to about $7 \mathrm{kPa}$ gauge. Although suit pressures are typically higher than that, $7 \mathrm{kPa}$ was used because it was high enough to support the suit, but not so high as to make constraining the leg and boot section of the suit difficult. This test configuration is shown in Fig. 1.

In order to simulate a dust storm on the Martian surface, particulates can be fed into the top of the MARSWIT about $4 \mathrm{~m}$ from the test section. The feed hopper was filled with a basaltic dust, and dropped into the air stream at varying speeds. Even at a wind speed of $10 \mathrm{~m} / \mathrm{s}$, the particles dropped to the floor of the tunnel before reaching the test section. Since this test was carried out at terrestrial pressures, this corresponds to the same dynamic pressure that would occur at $100 \mathrm{~m} / \mathrm{s}$ on the Martian surface. Although it has been suggested that some landforms would require such wind velocities to be formed, ${ }^{8}$ this is far in excess of any of the wind speeds measured at either the Viking or Pathfinder sites. So it was decided that particles with the correct mass were too heavy.

It should be noted that how long particles remain suspended depends on particle size, and that smaller particles could have reached the test section. But the use of very small particles introduces both safety concerns for those in and

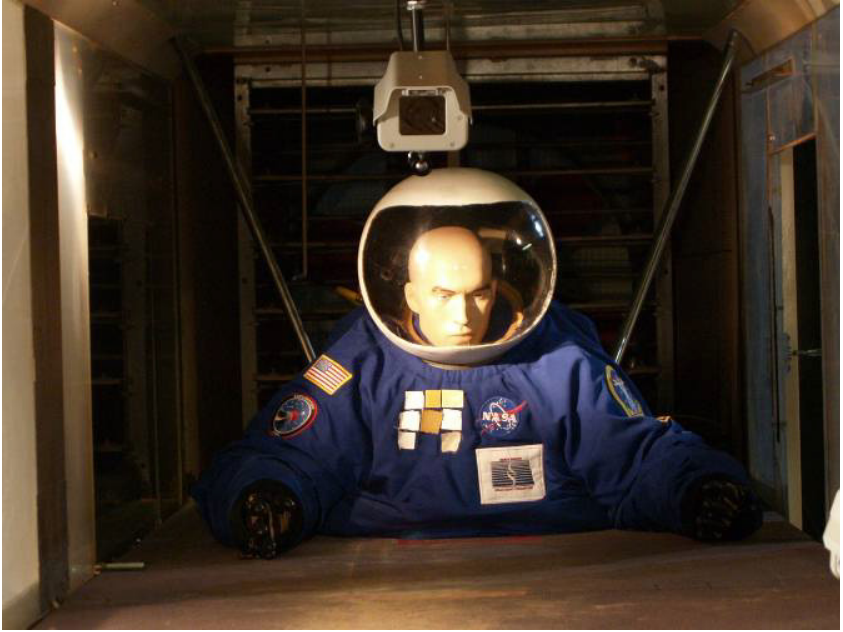

Figure 1. NDX-1 suit in the test position in the MARSWIT. Note the 9 square patches of fabric samples on the space suit chest. around the tunnel, and cleaning and maintenance concerns for the facility. Thus, there were constraints on the minimum particle sizes that could be used for this film project.

So the decision was made to utilize powdered walnut shells with a nominal particle size of $150 \mu \mathrm{m}$ to simulate the Martian dust. The density of walnut shell is $1.2 \mathrm{~g} / \mathrm{cm}^{3}$, which is about 25 percent of the density of basaltic rock, which makes up the bulk of the Martian surface. The Mho hardness is 3.5, which is considerably less than typical basaltic rock $(\approx 6)$, but still harder than the materials we were abrading. So although the dust used in these tests was not ideal to evaluate the abrasion of the fabrics, it would at least give some indications of abrasion resistance. Since infiltration is a function of particle size and energy, walnut shell again will give an indication. 
Nine fabric materials were chosen for testing. Six were kindly provided by ILC Dover, and three by the University of North Dakota (UND). The ILC Dover fabrics included an Apollo-era FEP of the type that was used on the Apollo lunar surface suits, Orthofabric of the type that is currently used for the outer lay of the Space Shuttle and International Space Station suits, and four experimental fabrics. These include Ortho-fabric with a silicone backing layer to keep dust from reaching the inner layers, silicone backed Kevlar, silicone-backed Vectran, and a Tyvek paper which has been suggested as a disposable over-garment. The UND fabrics included NDX1OL, a blue cottonnylon fabric that makes up the outer layer of the NDX-1 suit used in the tests, NDX1RL which made up the restraint layer of the suit used during the tests, and NDX2OL an advanced double layer fabric. The nine fabric samples were attached to the NDX-1 suit using double sided toupee tape in a three-by-three grid on the chest of the suit, and occupied an area about 20 to $50 \mathrm{~cm}$ above the floor of the MARSWIT, so effectively out of the floor's boundary layer. They are clearly visible in Fig. 1. A map indicating which samples were in which position is shown in Fig. 2.

In addition to the fabric patches, abrasion of the polycarbonate visor was monitored by masking sections of the visor with tape. Part of the tape was removed after each run, so that these sections of the visor were exposed to different amounts of dust than the bulk of the visor. These sections were then inspected for abrasive damage caused by the dust after the runs.

At the conclusion of each run in the MARSWIT, the suit and samples were photographed. The samples were carefully peeled off of the suit, carefully wrapped in a sheet of waxed weighing paper, and placed in individual zip lock bags for later analysis. The suit was then removed from the wind tunnel and dust was removed from both the suit and the MARSWIT with a vacuum cleaner. After both the suit and the wind tunnel were clean, the suit was placed back into the MARSWIT and a fresh set of samples was affixed to the suit.

Four runs were made at terrestrial pressure, and one at Martian pressure. All of the runs except one were for 10 minutes. Ten minutes was chosen as the maximum time because the bin holding the walnut shell particles could only

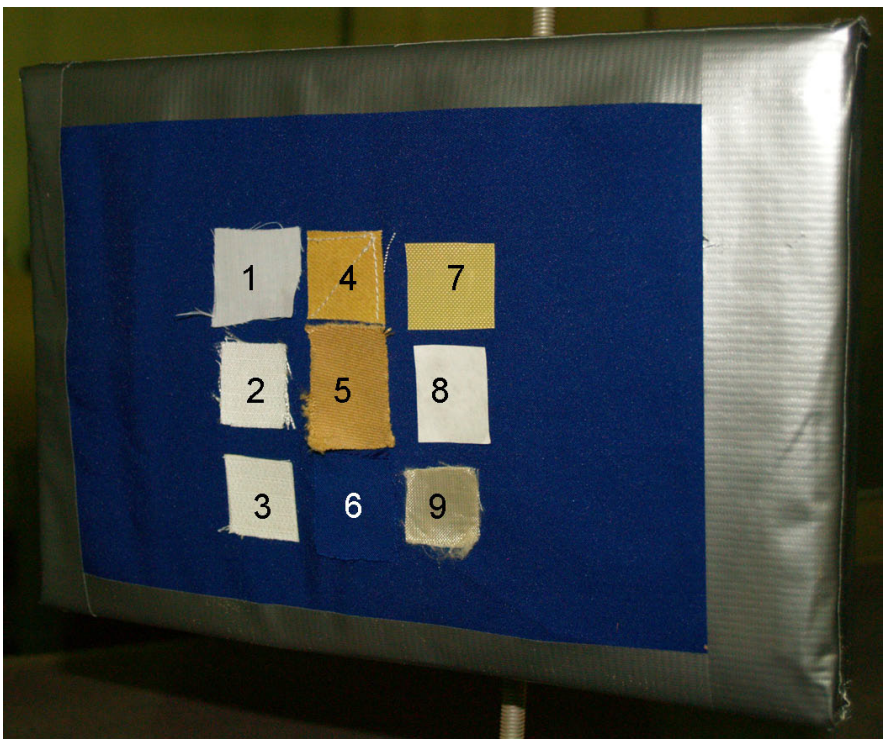

Figure 2. Fabric samples for the Martian pressures tests in the MARSWIT. (1) Apollo-era FEP, (2) Orthofabric, (3) silicone backed Orthofabric, (4) NDX2OL, (5) NDX1RL, (6) NDX1OL, (7) silicone backed Kevlar, (8) Tyvek, and (9) silicone backed Vectran.

hold enough material for about that length of time. Run 3, at $10 \mathrm{~m} / \mathrm{s}$, was run for only $3 \mathrm{~min}$, for fear of excessively damaging the polycarbonate face shield. Run 5 was run at the highest velocity thought to be relevant to the Martian environment, $35 \mathrm{~m} / \mathrm{s}$. Run 4 was set to have the same dynamic pressure as Run 5 . All tests were carried out at room temperature. The specific characteristics of each run are shown in Table I.

The experimental set-up was changed for the Martian pressure run. Due to the tight filming schedule, the suit was shipped to the site of the dust-devil test before the Martian atmosphere test could be run. So the samples were mounted on a piece of NDX1OL, on a padded board to mimic the spacesuit mounting. This was placed inside the MARSWIT at the same position they occupied when attached to the suit, as shown in Fig. 2.

Table I. Test Parameters for Each of the Test Runs in the MARSWIT

\begin{tabular}{cccccc}
\hline \hline Run \# & $\begin{array}{c}\text { Air density, } \\
\mathrm{kg} / \mathrm{m}^{3}\end{array}$ & $\begin{array}{c}\text { Wind velocity, } \\
\mathrm{m} / \mathrm{s}\end{array}$ & $\begin{array}{c}\text { Dynamic } \\
\text { pressure, } \\
\mathrm{Pa}\end{array}$ & $\begin{array}{c}\text { Walnut shell } \\
\text { kinetic energy, } \\
\mathrm{nJ}\end{array}$ & $\begin{array}{c}\text { Sand kinetic } \\
\text { energy, }{ }^{*} \\
\mathrm{~nJ}\end{array}$ \\
\hline 1 & 1.23 & 4 & 9.8 & 32 & 130 \\
2 & 1.23 & 3 & 5.5 & 18 & 73 \\
3 & 1.23 & 10 & 61.3 & 200 & 810 \\
4 & 1.23 & 3.5 & 7.5 & 25 & 100 \\
5 & 0.012 & 35 & 7.4 & 2500 & 10000 \\
\hline \hline
\end{tabular}

*Although runs were made using walnut shell, this column gives the energy for sand particles under the same conditions. 
Post-test samples were imaged under a Leica MZ16 optical microscope fitted with digital image capture. The fabric samples were imaged at $10 \times, 25 \times, 50 \times$, and $100 \times$ magnification. Selected samples of the fabrics $15 \times 17 \mathrm{~mm}$ were cut out and mounted in a sample handler that was designed to fit within the Field Emission Scanning Electron Microscope (FESEM). Those samples were then imaged with a Hitachi Model S 4700 FESEM using electron acceleration voltages ranging from 2 to $3 \mathrm{kV}$ at $50 \times$ to $1000 \times$ magnification. The low acceleration voltages enabled the samples to be imaged without the addition of conducting coatings.

\section{B. Dust Devil Tests}

The Martian dust devil tests were carried out at Showbiz Studios (Van Nuys, CA) using a large fan-created vortex. Two different Martian simulants were used in this test. The first was Fuller's Earth, a fine particle size (down to a few $\mu \mathrm{m}$ ) clay material that contains montmorillonite, which may be similar to some Martian minerals. ${ }^{9}$ The

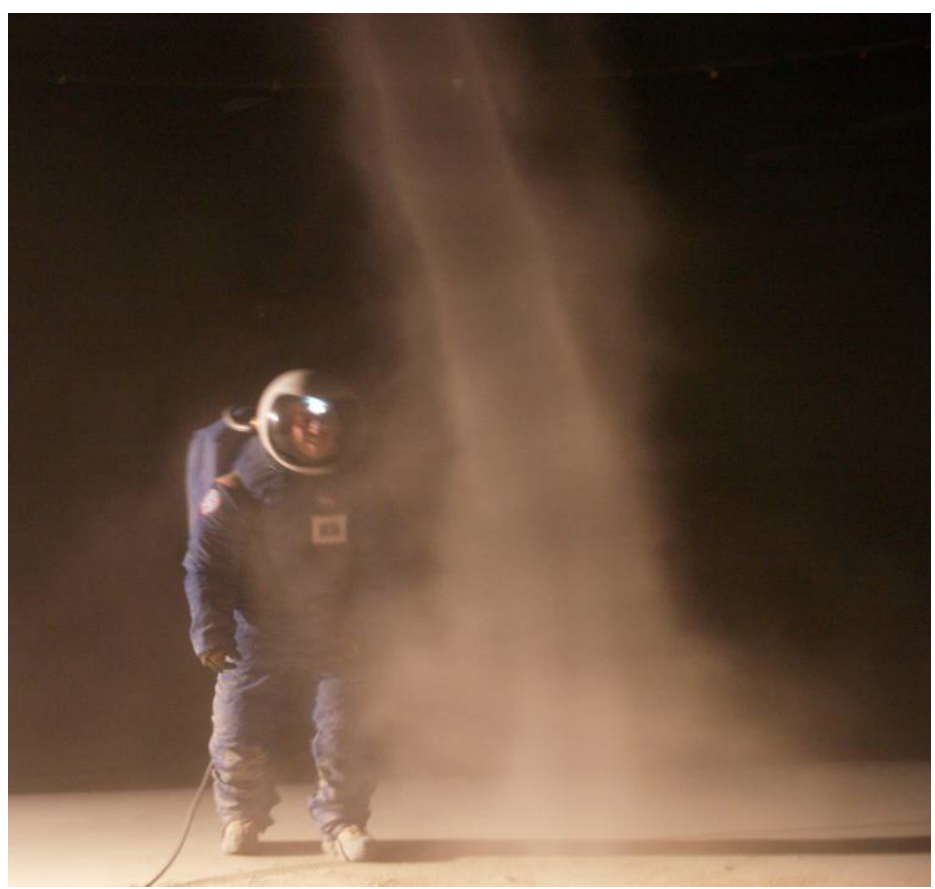

Figure 3. Lee in NDX-1 suit walking into an artificial dust devil of Fullers Earth. second simulant was JSC Mars-1, a simulant that has similar optical properties to Martian dust, but had a minimum particles size of about $1 \mathrm{~mm} .{ }^{10}$ One of the authors (Lee), wearing the NDX-1 space suit with the pressure maintained at $20 \pm 2 \mathrm{kPa}$ gauge $(3.0 \pm 0.2 \mathrm{psig})$, walked through the dust devil to judge both subjectively and objectively how the suit performed under these conditions. A photograph of a test in progress is shown in Fig. 3.

\section{Results and Discussion}

\section{A. MARSWIT Tests}

At the conclusion of Run 4, the last run with the full suit installed in the MARSWIT, the suit was carefully disassembled and photographs were taken at each disassembly stage to document the amount of dust that infiltrated through the outer blue layer (of NDX1OL) and through the inner NDX1RL restraint layer. Figure 4 shows a few representative photographs of that analysis.

Figure 4(a) shows the position and condition of the NDX-1 at the conclusion of test Run 4, just before disassembly. Note that most of the dust that can be seen on the suit is on the lower portion of the suit. The height of dust adhering to the suit depended, predictably, on the wind speed. Only in Run 3, with a speed of $10 \mathrm{~m} / \mathrm{s}$, was there a significant amount of dust on the visor. Concern of significantly damaging the visor limited this run time to 3 min. It can be noted, however, that the dust in this test did rise up over the collar of the blue outer layer, and some dust was observed on the lower portion of the helmet. Note that the arm position in this test is extended away from the body. Although the arm position varied slightly from test to test, having the arms so close to the body to shadow it, or completely extended so that the wind might blow up the sleeve, were extremes that were avoided.

Figure 4(b) shows a close-up of the protective tape patches that were put on the visor to shield it from additional exposure. A patch was added after each test, so in later analysis any visor damage could be assessed. The patch that was applied after the $4 \mathrm{~m} / \mathrm{s}$ test is visible near the chin of the mannequin, and those added after the $3 \mathrm{~m} / \mathrm{s}$ and the $10 \mathrm{~m} / \mathrm{s}$ runs are on the other side of the visor, approximately across from the mannequin nose in the photo. Visual inspection of the areas protected by the tape patches showed no difference with the rest of the visor. Similarly, no degradation of the visor was observed after dust was removed with a brush.

Figure 4(c) illustrates that a significant amount of dust flew up the sleeve of the suit. This is undoubtedly due in large part to the arm position being somewhat aligned with the direction of the wind flow. However, as can be seen in Fig. 4(d), only a little of that dust made it as far up the arm as to deposit on the glove joint. That which did, did not impair the working of the glove attachment mechanism. 


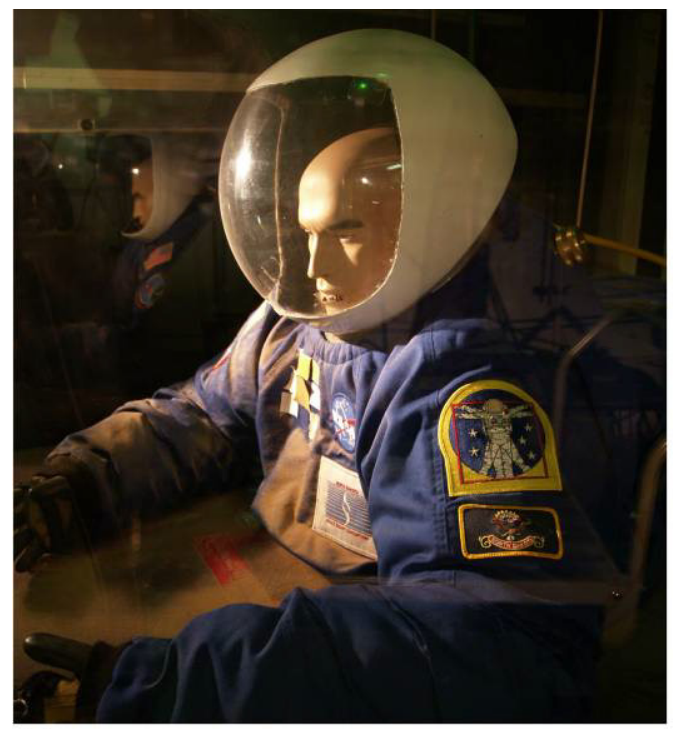

(a)

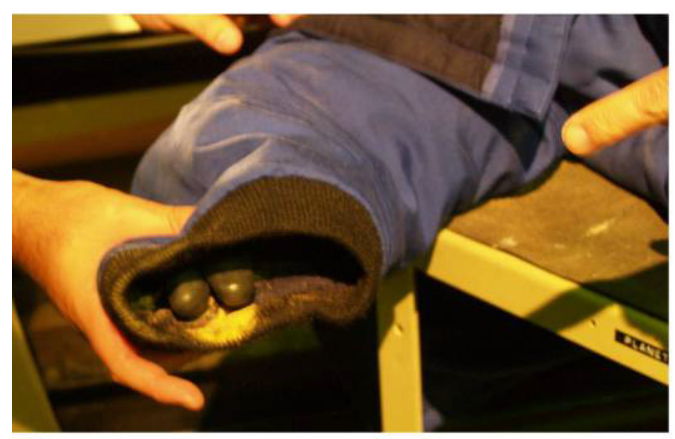

(c)

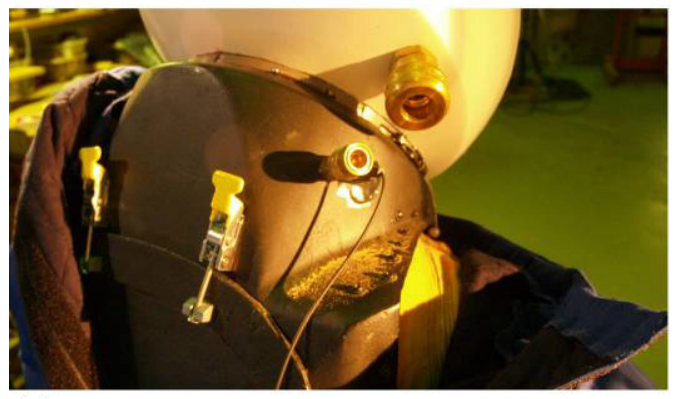

(e)

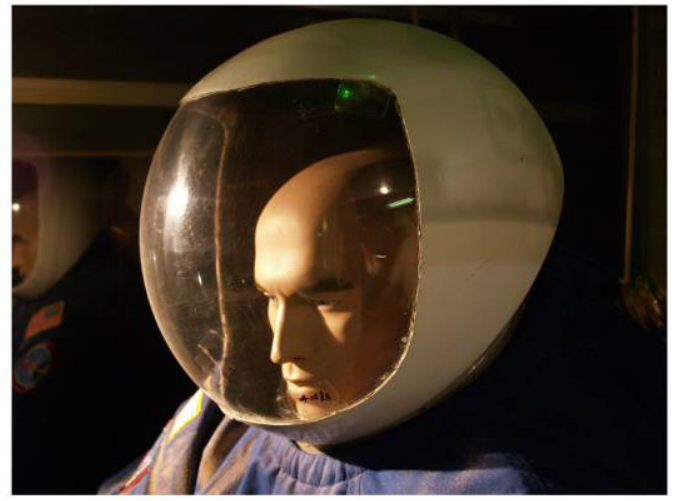

(b)

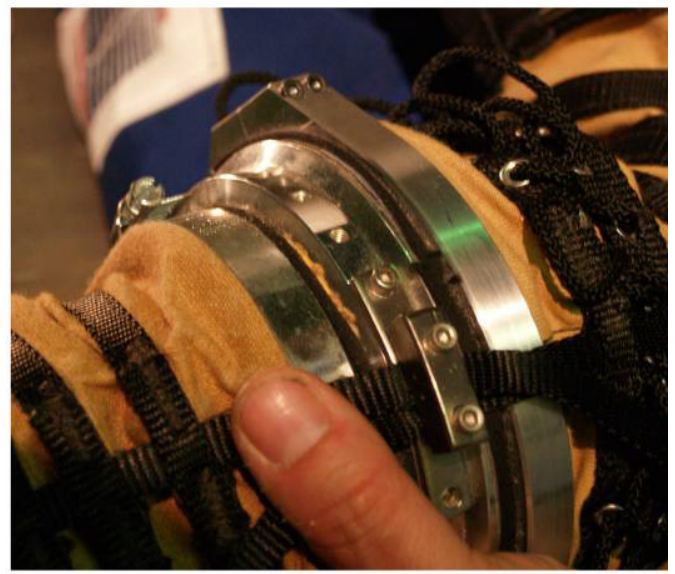

(d)

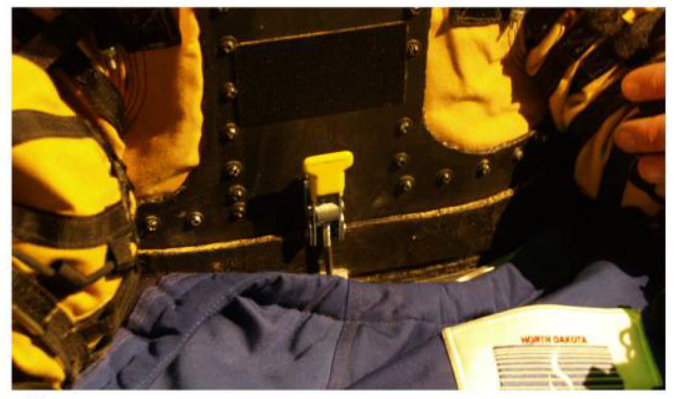

(f)

Figure 4. MARSWIT tests. (a) NDX-1 space suit in MARSWIT showing geometry of suit position and overall dust pattern. (b) A protective tape patch can be seen near the chin of the mannequin. (c) A large amount of dust was blown up the sleeve of the outer garment. (d) Despite the large amount of dust that blew up the sleeve, little of it contaminated the glove joint mechanism. (e) A significant amount of dust was blown under the outer garment near the helmet. (f) Some dust that was blown under the outer garment reached all the way down to the front of the waist joint.

Figure 4(e) shows that another quantity of dust entered around the neck of the outer layer, and settled on the horizontal surface of the helmet support. Some of this even dropped down as far as the front of the waist joint (Figure 4(f)). Again, the deposited dust deposited did not hamper the working of the suit mechanisms.

Virtually all of the dust that made it past the blue outer layer of the suit entered by the two paths described above, up the sleeve or down the collar. No significant fraction of the dust actually penetrated the the outer layer. Similarly, no dust was found to infiltrate the pressure garment layer. 


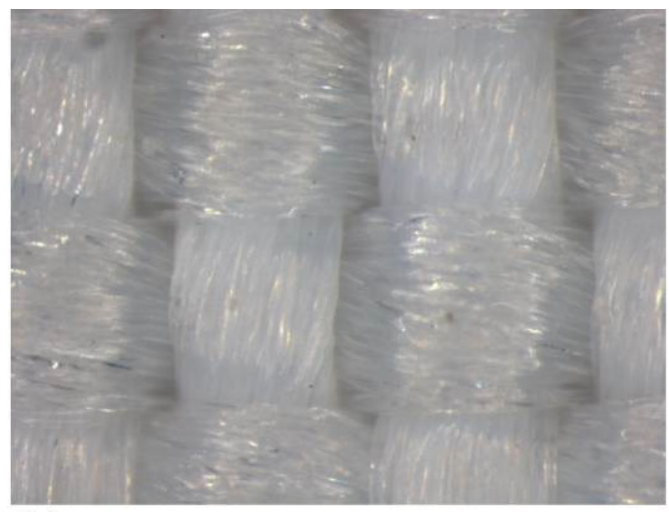

(a)

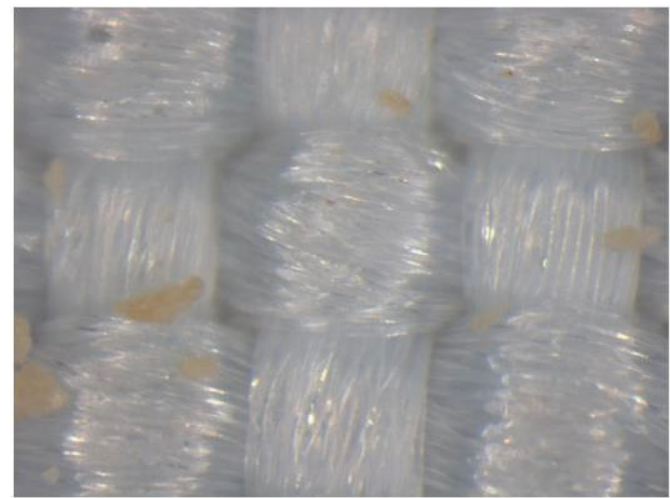

(c)

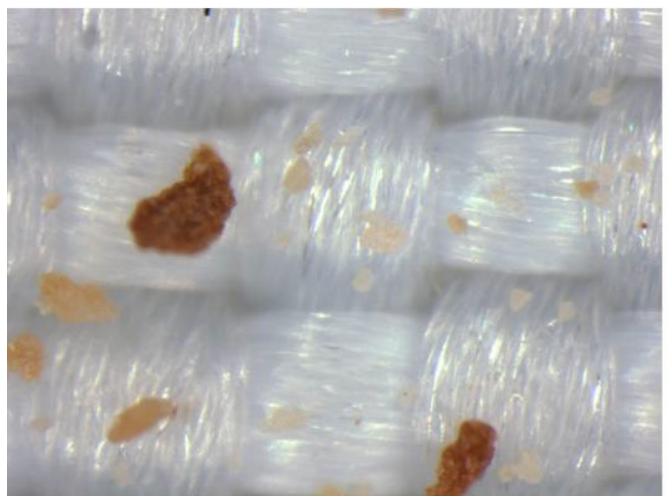

(e)

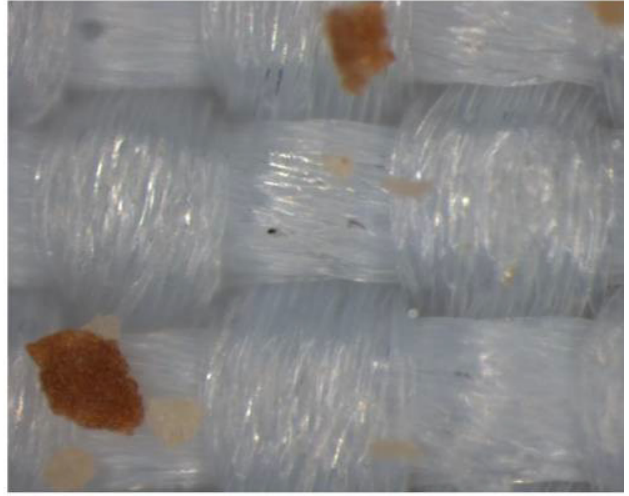

(b)

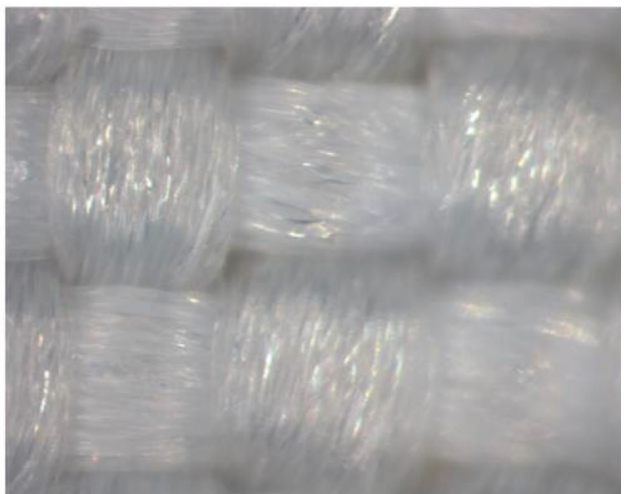

(d)

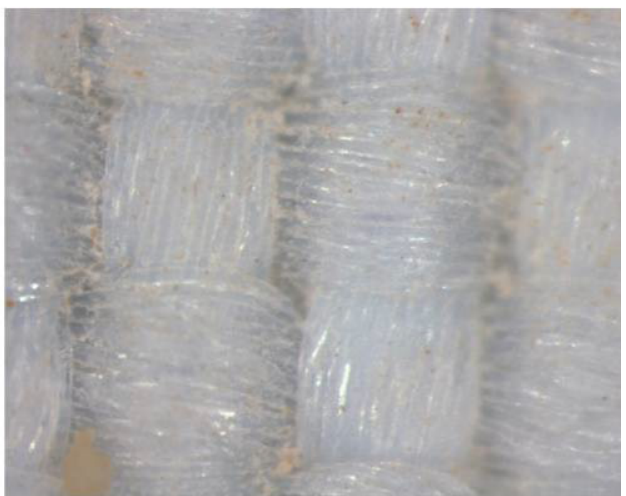

(f)

Figure 5. Optical photomicrographs of the Apollo-era FEP fabric exposed to test conditions at 100 $\times$ magnification. (a) Pristine Apollo-era FEP. (b) Apollo-era FEP subjected to $150 \mu \mathrm{m}$ walnut shell at $2 \mathrm{~m} / \mathrm{s}$ air for $10 \mathrm{~min}$. (c) Apollo-era FEP subjected to $150 \mu \mathrm{m}$ walnut shell at $6 \mathrm{~m} / \mathrm{s}$ air for $10 \mathrm{~min}$. (d) Apollo-era FEP subjected to $150 \mu \mathrm{m}$ walnut shell at $6 \mathrm{~m} / \mathrm{s}$ air for $3 \mathrm{~min}$. (e) Apollo-era FEP subjected to $150 \mu \mathrm{m}$ walnut shell at $3.5 \mathrm{~m} / \mathrm{s}$ air for $10 \mathrm{~min}$. (f) Apollo-era FEP subjected to $150 \mu \mathrm{m}$ walnut shell at $35 \mathrm{~m} / \mathrm{s}$ Martian pressure air for $10 \mathrm{~min}$.

Optical photomicrographs at $100 \times$ for the Apollo-era FEP fabric exposed to each of the test conditions are shown in Fig. 5. No abrasion is seen in the fabrics exposed to any of the conditions. This is the case for all nine of the fabric types tested.

Figure 6 shows the same samples under the FESEM. Although the exposure time was short, evidence of abrasion at high magnification was seen. Minimal defects were observed in the pristine FEP, as is illustrated by Fig. 6(a), which shows the appearance of the FEP at 250×. The FEP exposed to wind-blown dust at $2 \mathrm{~m} / \mathrm{s}$ resulted in the accumulation of dust particles on the surface of the fabric, but no abrasion was noted (Fig. 6(b)). 


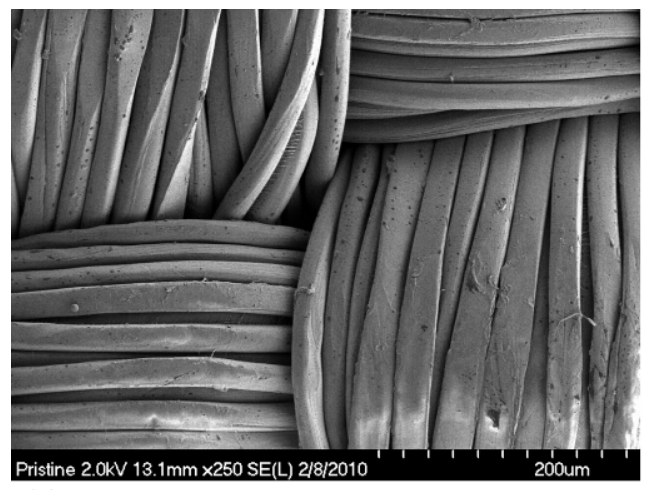

(a)

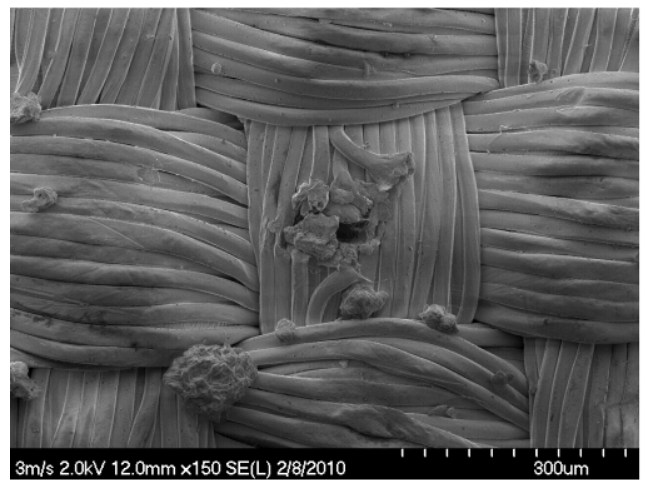

(c)

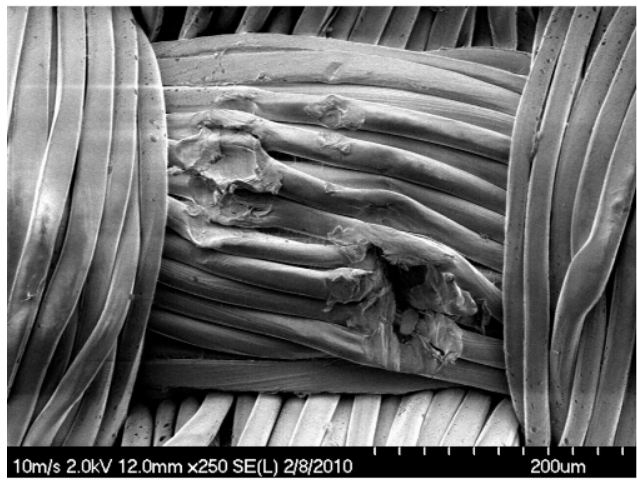

(e)

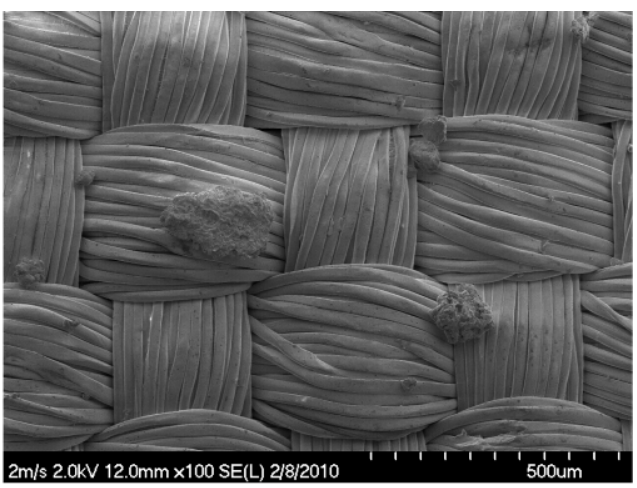

(b)

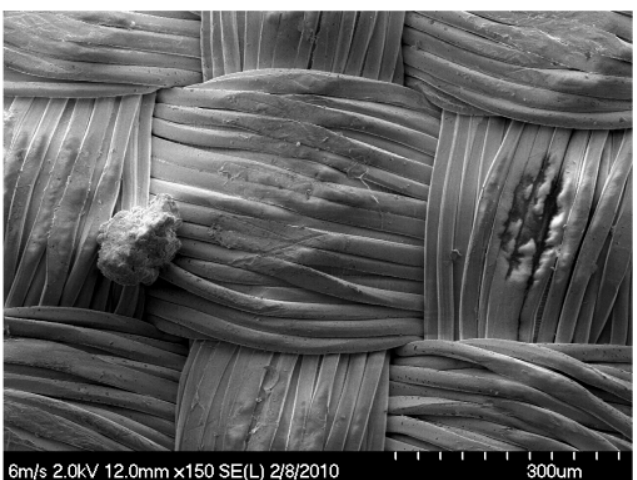

(d)

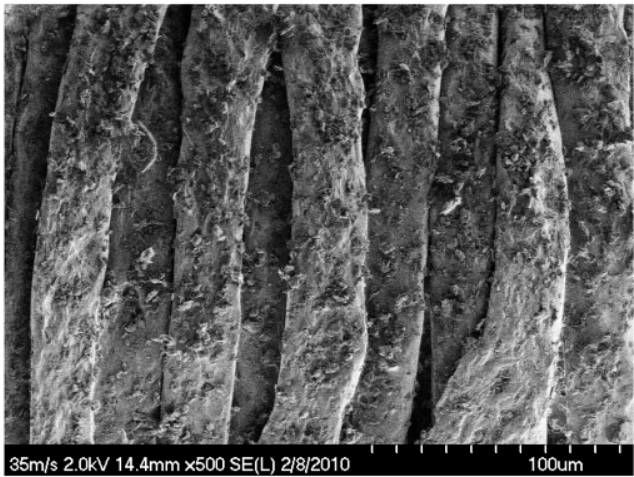

(f)

Figure 6. Apollo-era FEP fabric samples under the Field Emission Scanning Electron Microscope (FESEM). (a) Pristine FEP fabric at high magnification in the FESEM exhibit minimal defects. (b) FEP fabric subjected to $2 \mathrm{~m} / \mathrm{s}$ winds show particle build-up, but no fiber damage. (c) FEP fabric subjected to $3.5 \mathrm{~m} / \mathrm{s}$ winds show occasional fiber damage. (d) FEP fabric subjected to $6 \mathrm{~m} / \mathrm{s}$ winds show more frequent fiber damage. (e) FEP fabric subjected to $10 \mathrm{~m} / \mathrm{s}$ winds show frequent fiber damage. (f) FEP fabric subjected to $35 \mathrm{~m} / \mathrm{s}$ winds at Martian pressures show broken walnut shell, but no fiber damage.

But as the wind velocity increased from $3.5 \mathrm{~m} / \mathrm{s}$ to $6 \mathrm{~m} / \mathrm{s}$ to $10 \mathrm{~m} / \mathrm{s}$, an increasing amount of fiber damage was observed (Figs. 6(c), (d), and (e)). The damage appeared as pits or craters in the fibers that appeared to be about the same size as the particles. This leads to the belief that each was caused by a single collision with a particle. There were more of these pits seen as the velocity increased. At $10 \mathrm{~m} / \mathrm{s}$ it was estimated that 2 to 5 percent of the weave squares were damaged. At the higher velocities, more of the pits appeared to fully penetrate the fibers. Whereas the pit shown in Fig. 6(c) was one of only two on the entire $1 \mathrm{~cm}^{2}$ sample to fully penetrate fibers, most of those at $10 \mathrm{~m} / \mathrm{s}$ were full penetrations. In the sample exposed to $6 \mathrm{~m} / \mathrm{s}$ particle-laden wind both the occurrence and extent of the damage was intermediate. 
But under Martian pressure and $35 \mathrm{~m} / \mathrm{s}$ dust laden wind (Fig. 6(f)), a completely different phenomenon is observed. There were no damage pits and no large $(150 \mu \mathrm{m})$ particles observed on the fibers. Instead the fibers were densely covered with fine particles, no more than about $10 \mu \mathrm{m}$ across. Apparently, the larger walnut shell particles were broken into these fine particles before they reached the samples. A $10 \mu \mathrm{m}$ particle only contains about 0.03 percent of the kinetic energy of a $150 \mu \mathrm{m}$ particle traveling at the same speed, so it is not surprising that they would do dramatically less damage to the fibers. But that the particles were so thoroughly pulverized is remarkable, given that the $150 \mu \mathrm{m}$ particles entered the air stream just $4 \mathrm{~m}$ before hitting the fabrics. The free stream velocity was $35 \mathrm{~m} / \mathrm{s}$, so the comminution occurred in the fraction of a second required to travel that distance. The Reynolds number of the air during the test was calculated to be on the order of 30,000 , so the flow was dominated by turbulence, which certainly favors collisions, but still the process appears to be remarkably efficient.

There are consequences of testing the fabrics under conditions that break up the particles. Whereas that larger $(150 \mu \mathrm{m})$ walnut shell particles sit on top of the fabrics, the smaller particles (few $\mu \mathrm{m})$ enter the fabrics and coat the individual fibers. Thus, the smaller particles adhere better. In addition, as the fibers within the fabric move against one another during normal use, fiber abrasion could become significant, perhaps causing the type of fiber wear and shredding observed in the outer layer of the Apollo space suits. ${ }^{11}$ Figure 6(f) looks remarkably like the FESEM micrographs of the Apollo suit fabric worn on the moon (Fig. 7).

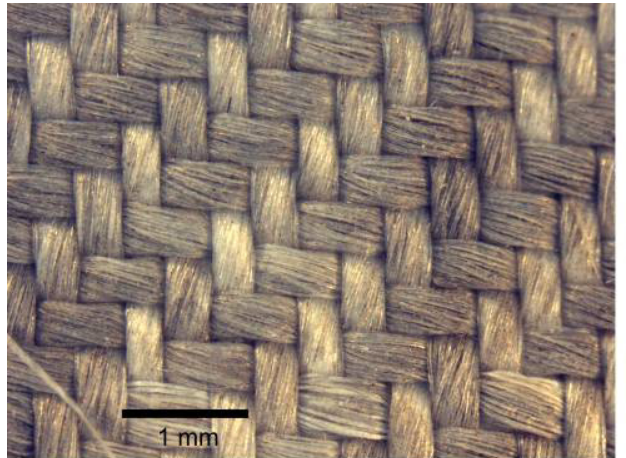

(a)

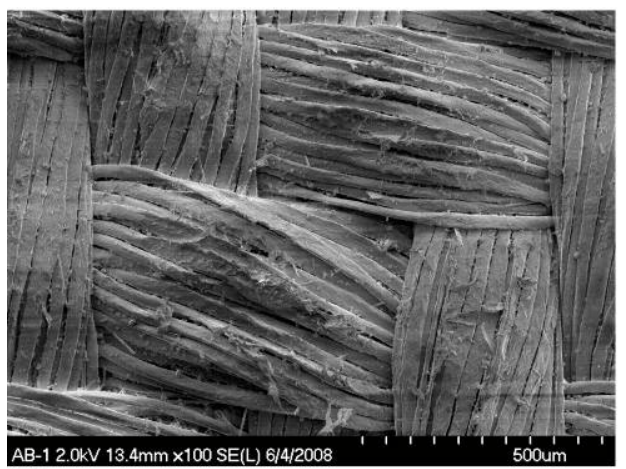

(c)

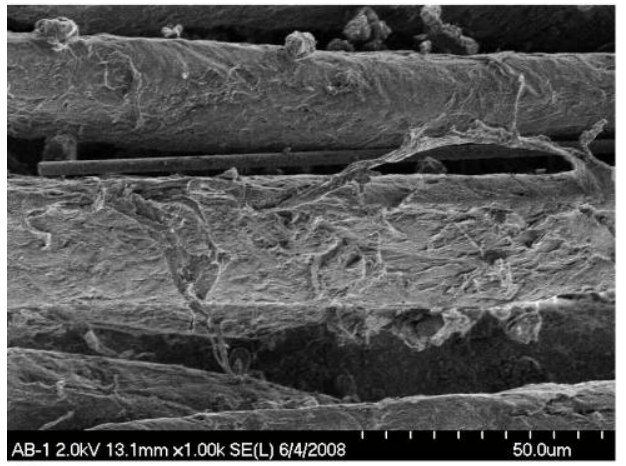

(e)

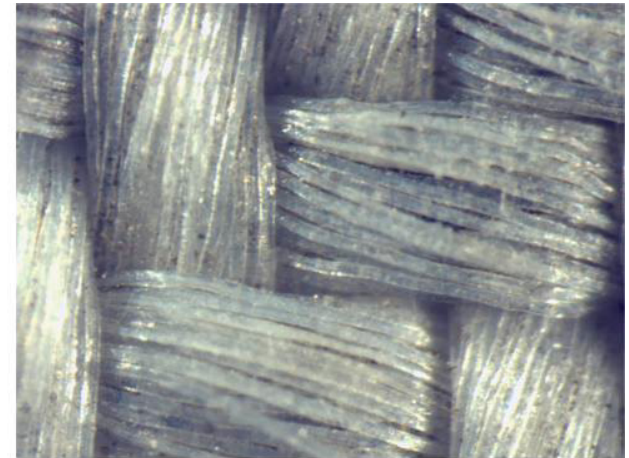

(b)

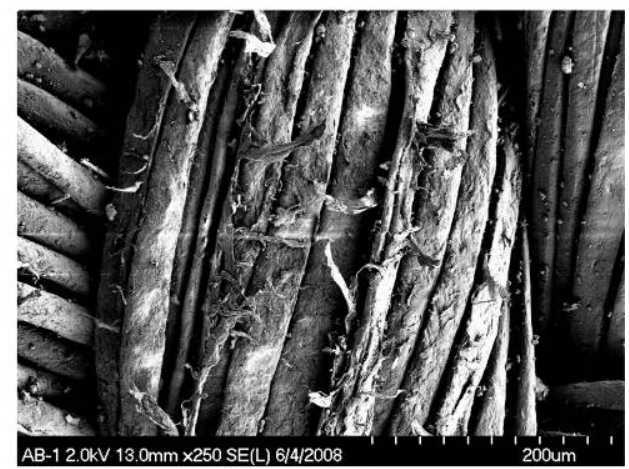

(d)

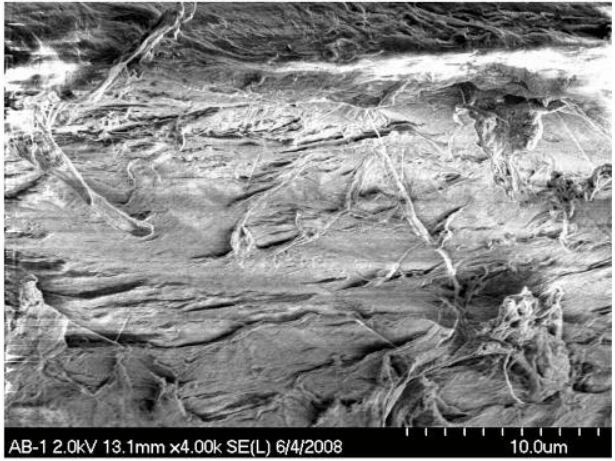

(f)

Figure 7. Photomicrographs of fabric from the left knee of Apollo 12 astronaut Alan Bean's suit. (a) and (b) Optical. (c) to (f) FESEM. 
This also illustrates a danger when trying to physically simulate an exotic environment such as the surface of Mars. Because of the different acceleration of gravity and the different atmospheric density, every simulation must make compromises. By using walnut shell particles the gravity was compensated for, but not the hardness of the particles. By working at terrestrial pressure either the dynamic pressure or the kinetic energy of the particles can be simulated, but not both. In this study, there was a synergistic effect between the two sets of choices made (compensate for gravity and generate the correct dynamic pressure) that resulted in a completely unexpected outcome. The particle size was dramatically reduced before it contacted the fabric.

Figure 8 shows the photomicrographs of all nine fabric samples exposed to the Run 5 conditions at $100 \times$. The 10- $\mu \mathrm{m}$-sized walnut shell particles can be seen in all of the samples. On the Martian surface, it seems unlikely that individual dust grains would be shattered as they travel through the atmosphere or impact the fabric of a space

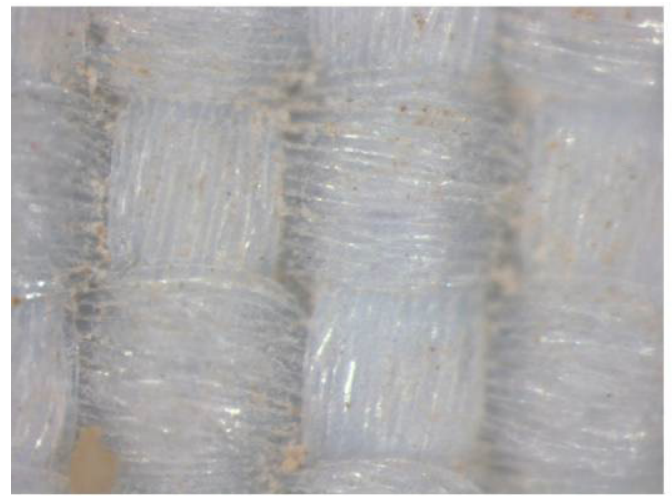

(a)

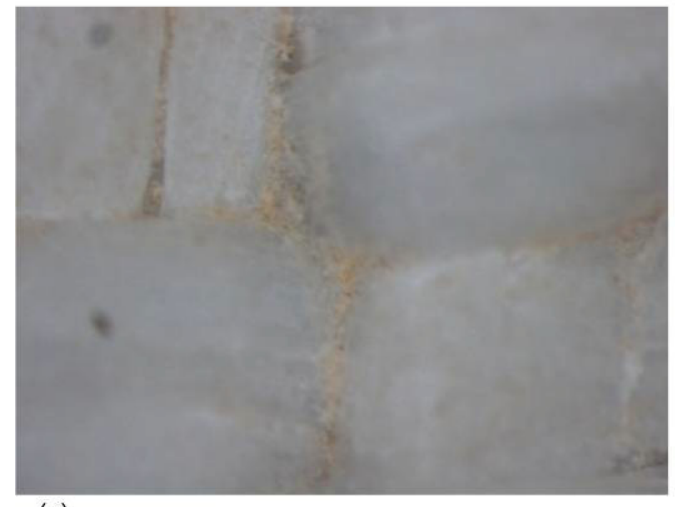

(c)

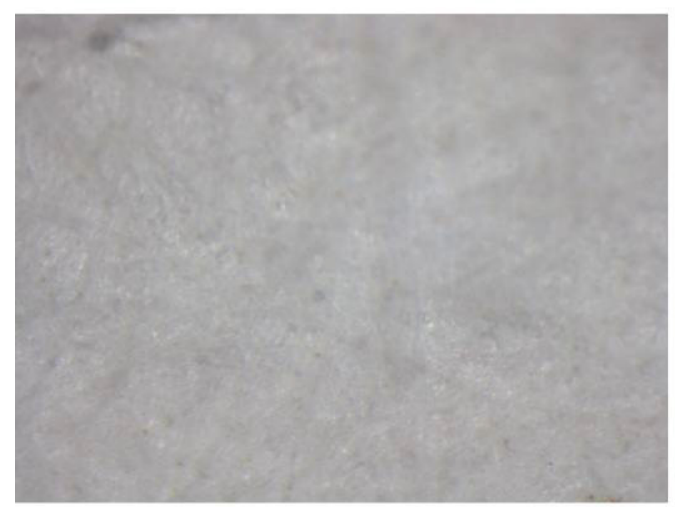

(e)

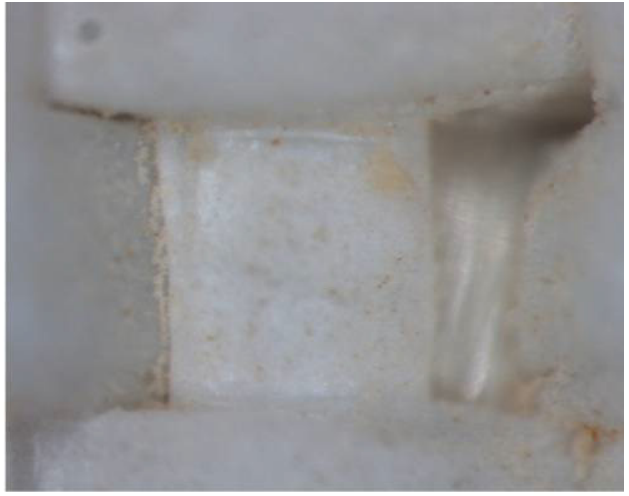

(b)

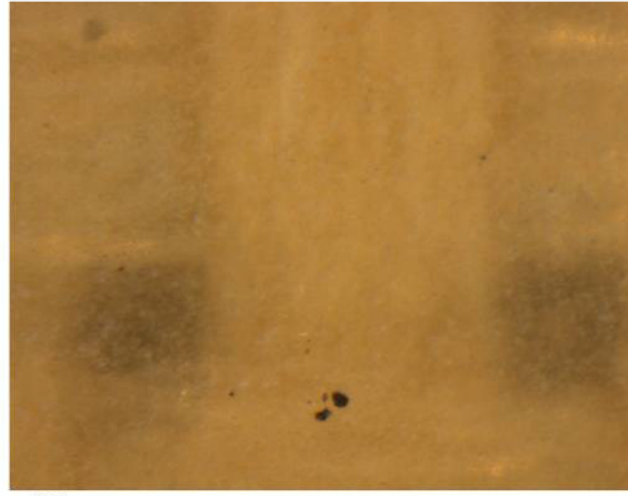

(d)

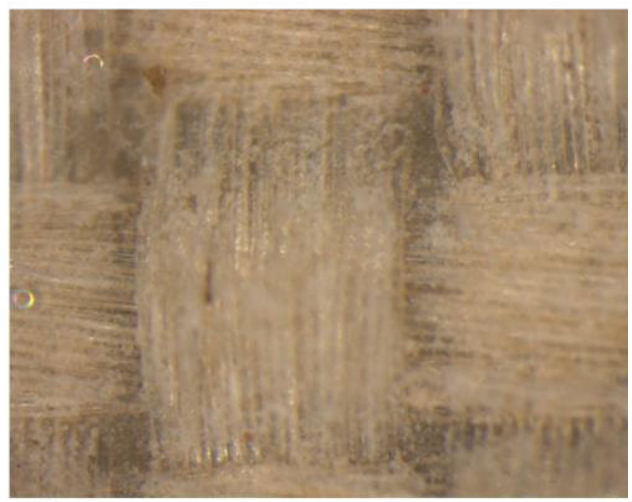

(f)

Figure 8. Photomicrographs of fabric samples subjected to $150 \mu \mathrm{m}$ walnut shell at $35 \mathrm{~m} / \mathrm{s}$ Martian pressure air for 10 min at 100x magnification (Run 5 conditions). (a) Apollo-era FEP. (b) Orthofabric. (c) Silicone-backed orthofabric. (d) Silicone-backed Kevlar. (e) Tyvek. (f) Silicone-backed Vectran. 


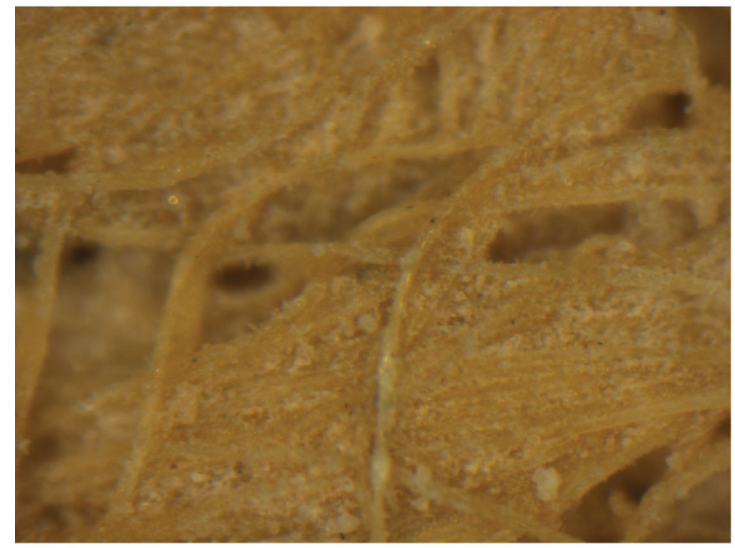

(g)

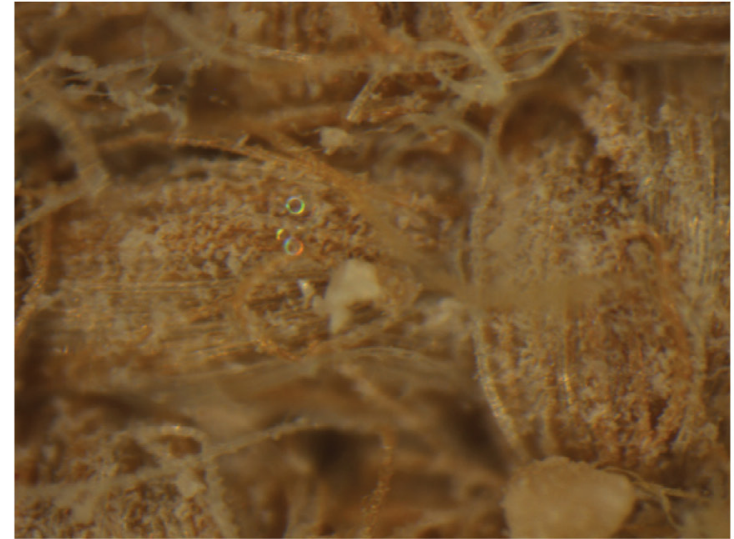

(h)

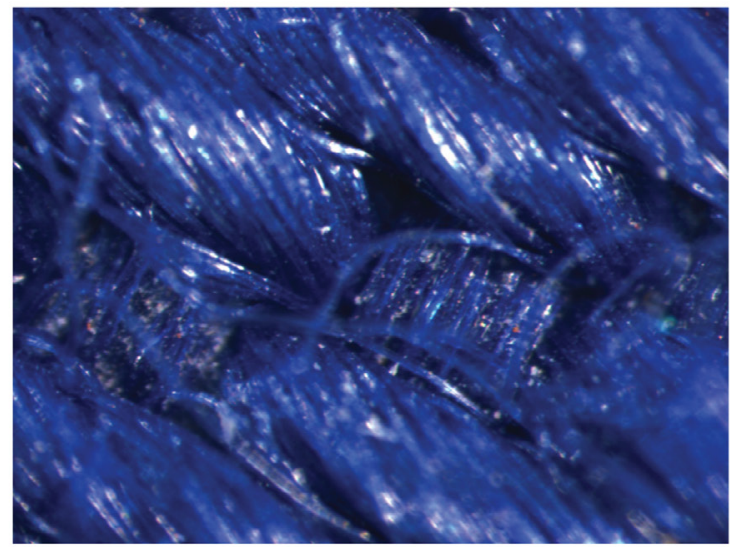

(i)

Figure 8. Concluded. (g) NDX2OL. (h) NDX1RL. (i) NDX1OL.

suit. However, it is likely that many of the particles which are most easily moved by the Martian winds would be agglomerates. It has been observed in previous experiments in the MARSWIT that at high wind speeds, particle agglomerates are moved, and shatter on impact either with a solid surface ${ }^{3}$ or a fabric. ${ }^{2}$ The result is that at high velocity small particles tend to coat surfaces with smaller particles rather than to abrade them. Thus, as a first approximation, more problems with space suits on the Martian surface will probably be associated with coating and clogging of mechanisms than abrasion of the fabrics.

\section{B. Dust Devil Tests}

The dust devils were produced by first spreading a quantity of Martian dust simulant on the floor, and then turning on the large fan. The created a vortex that pulled the dust up off of the floor. The dust devils were clearly visible. After the dust devil was created, the suit subject (Lee) walked from a clear area into the storm. He then performed routine tasks while in the dust devil, such as walking, bending over, and picking objects up. As the suit subject encountered the various dust devils generated for the test, he commented on being able to distinctly hear the sound of impinging airborne particles on his helmet (noticeable in spite of the noise of the internal air-circulating fan), the transient (1 to $2 \mathrm{~s}$ ) loss of visibility of background features through the thickest column section of the dust devil, and also the good opportunity he was afforded to observe intricate eddies and circulation patterns associated with the dust devil. No significant dynamic pressure on the suit nor any particular discomfort were felt while transiting in and out of the dust devil.

The results of the performance of the NDX-1 space suit in the dust devil tests are summarized in Fig. 9. Figure 9(a) shows that, as expected, there was a significant amount of dust that adhered to the entire suit- - helmet to boots. Figure 9(b) shows a close up of the left shoulder in order to illustrate the extent of the dust coverage. Due to the swirling winds raising the dust simulant from the floor to well above the top of the suit, the dust coverage was nearly uniform over the entire surface of the suit. Figure 9(c) demonstrates that the visor was covered as well. 


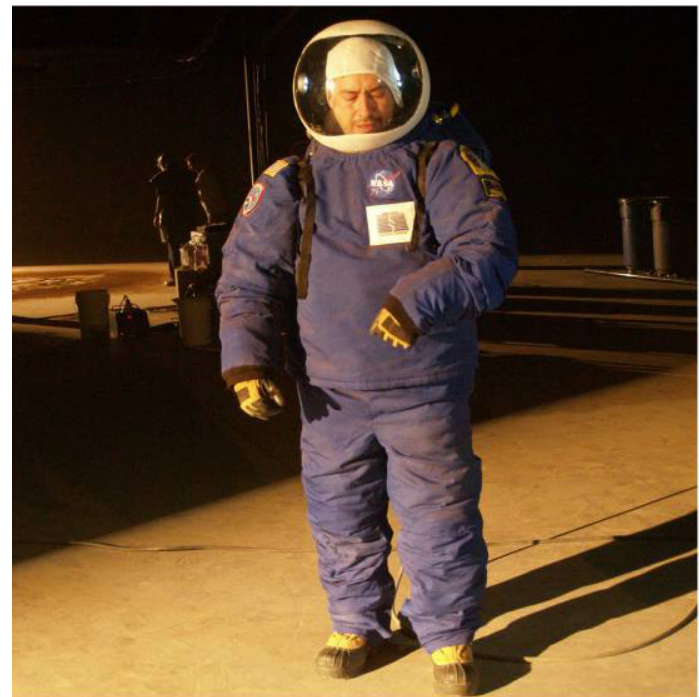

(a)

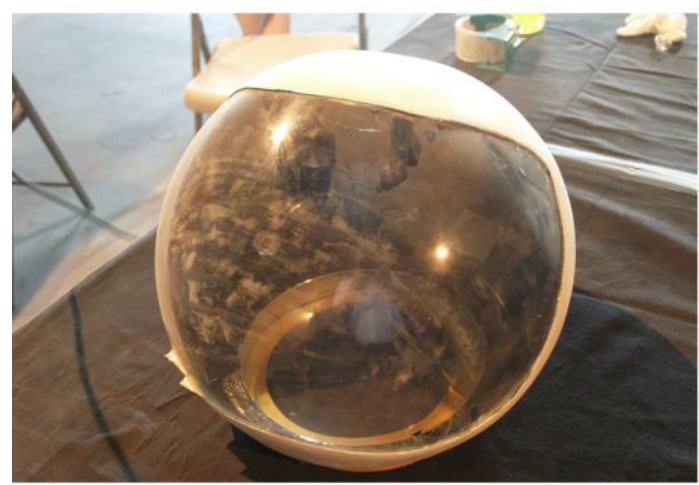

(c)

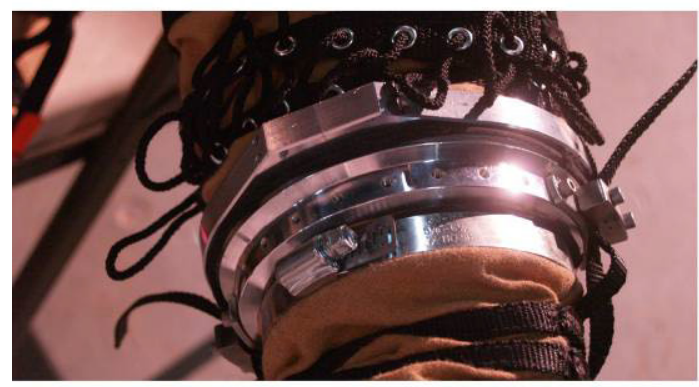

(e)

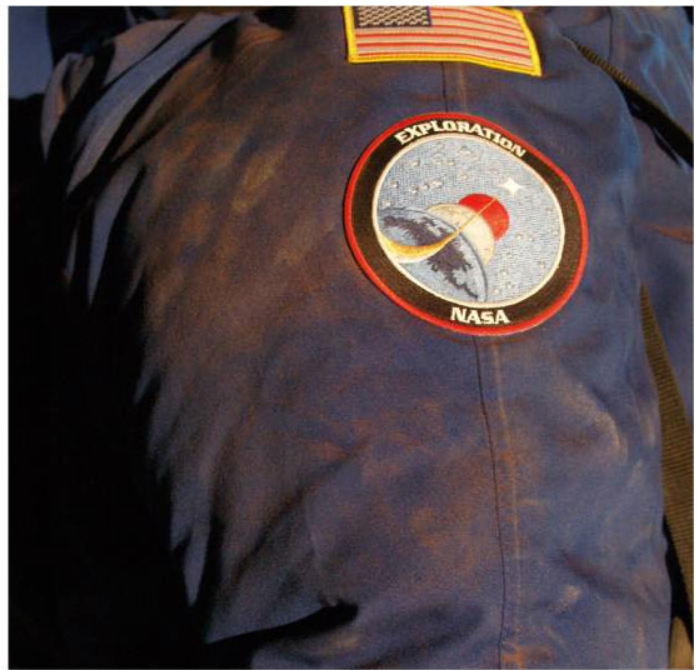

(b)

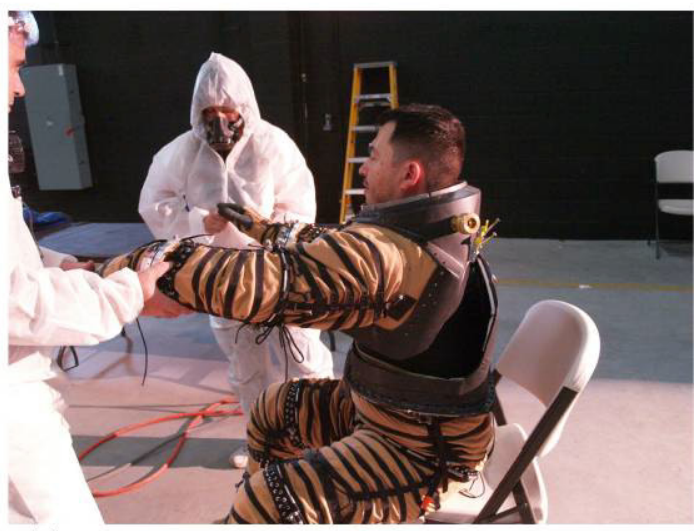

(d)

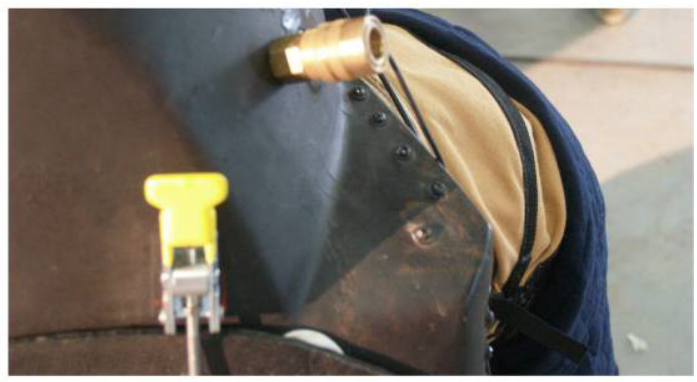

(f)

Figure 9. (a) JSC-1 Martian simulant coats NDX-1 space suit after exposure to artificial dust devil. (b) Closer view of JSC-1 Martian simulant coating NDX-1 space suit after exposure to artificial dust devil. (c) A large amount of dust adhered to the visor during the dust devil test. (d) Despite the large amount of dust that coated the outer layer, little of it contaminated the pressure garment. (e) Despite the large amount of dust that coated the NDX-1 outer layer, almost none of it contaminated the glove joint mechanism. (f) A small amount of dust was blown under the outer garment and reached the helmet support. 


\section{Conclusions}

In order to assess abrasion and infiltration issues that might be encountered on the Martian surface, a pressurized NDX-1 spacesuit was exposed to windblown Martian dust simulants in the MARSWIT, and in a dust vortex machine. In addition, nine fabric samples were affixed to the suit in the MARSWIT tests.

The MARSWIT tests showed that, even under these short times, fabric abrasion is initiated by pits that can break through individual filaments at wind speeds as low as $3.5 \mathrm{~m} / \mathrm{s}$ and terrestrial pressure. At a wind speed of $35 \mathrm{~m} / \mathrm{s}$ under Martian pressures, the walnut shell dust simulant was broken from $150 \mu \mathrm{m}$ particles to $10 \mu \mathrm{m}$ particles and smaller. These smaller particles penetrated the weave and became attached to individual fibers. Thus lodged, the individual fibers would be susceptible to abrasion as the fiber was worked under normal operations. Under high magnification, these closely resembled the Apollo fabrics worn on the lunar surface, though without the abrasive damage. The NDXOL1 outer garment allowed some infiltration of dust, but not enough to hamper the working of the mechanisms of the restraint layer underneath, such as the glove and helmet locks.

The NDX-1 suit performed well in the artificial dust devil tests. Visibility was maintained, and the subject in the suit was not hampered from performing routine tasks, such as walking, bending over, and picking objects up. Again the NDXOL1 outer garment allowed a small amount of dust infiltration, but not enough to hamper the working of the mechanisms of the pressure garment underneath.

Although the tests were preliminary, and the environments of relatively low fidelity, since lower pressure would be required for Mars conditions, no substantial issues were identified in protecting the suit and its wearer from the effects of wind-blown dust in the Martian environment.

\section{Acknowledgements}

The authors would like to thank the production crew from Yap films, who worked with us on the film project, "Storm Worlds". J. Ware of ILC Dover kindly presented six of the samples for the test. K. Smith, was indispensible as the operator of the MARSWIT, and provided many practical suggestions and improvements for wind tunnel tests.

\section{References}

\footnotetext{
${ }^{1}$ Gaier, J.R., "The Effect of Lunar Dust on EVA Systems During the Apollo Missions," NASA/TM-2005-213610/REV1, 2007.

${ }^{2}$ Fernandez W., "Martian Dust Storms: A Review," Earth, Moon and Planets, Vol. 77, 1997, pp. $19-46$.

3 Balme, M., and Greeley, R., "Dust devils on Earth and Mars," Rev. Geophys Res., Vol 44, 2006, RG3003, doi:10.1029/2005RG000188.

${ }^{4}$ Lee, P. and Thomas, P.C., "Longitudinal Dunes on Mars: Relation to Current Wind Regimes," J. Geophys. Res., 100(E3), 1996, pp. 5381-5395.

${ }_{5}^{5}$ Marshall, J., Bratton, C., Kosmo, J., and Trevino, R., "Interaction of Space Suits with Windblown Soil, Preliminary Mars Wind Tunnel Results," Lunar and Planetary Science Conference XXX, 1999, 1239.pdf.

${ }^{6}$ Gaier, J.R., and Perez-Davis, M.E., "Effect of Particle Size of Martian Dust on the Degradation of Photovoltaic Cell Performance," Solar Engineering 1992, edited by W. Stine, J. Kreider, and K. Watanabe, ASME, NY, 1992, pp. 867-73.

${ }^{7}$ Pollock, J.B., et al., "Properties and Effects of Dust Particles Suspended in the Martian Atmosphere," J. Geophys. Res., Vol. 84, 1979, pp. 2929-45.

${ }^{8}$ Greeley, R., White, et al., "Dust Storms on Mars: Considerations and Simulations," NASA TM-78423, 1977.

9 Toon, O.B., Pollock, J.B., and Sagan, C., "Physical Properties of the Particles Composing the Martian Dust Storm of 19711972," Icarus Vol 30, 1977, pp. 663-696.

${ }^{10}$ Allen, C.C., et al., "JSC Mars-1: Martian Regolith Simulant," Lunar and Planetary Science XXVIII, 1997, Paper 1797.pdf.

${ }^{11}$ Christoffersen, R., et al., "Lunar Dust Effects on Spacesuit Systems: Insights from the Apollo Spacesuits," NASA/TP_ 2009-214786.
} 